\title{
Industrialization Emission (Trace Metal, Nitrogen and Phosphorus) Modified Coastal Climate
}

\author{
Yongpeng Tong, Zhipeng Zhu \\ Shenzhen University, Shenzhen, China \\ Email: yongpeng@szu.edu.cn
}

Received 6 May 2015; accepted 18 August 2015; published 25 August 2015

\begin{abstract}
Objectives: As a result of global warming, precipitation is likely to increase at certain area (high latitudes). However, the mechanisms that human activity is influenced by global climate change are far from completely understood. We try to analyze the relationship between industrial emission (trace metal, nitrogen and phosphorus) and climate signature (precipitation) by Chinese industrialization progresses. Methods: Mainly by using the public data from Bulletin of Environment in China, Bulletin of Marine Environmental Status of China and some data of our experiments, we get the analyzed result. Results: Annual average temperature in China after industrialization is significantly increased, whereas annual average precipitation in China after industrialization is no significantly difference. Phytoplankton increases evaporation of seawater and the relative humidity. Phytoplankton biomass will be different in different stages of environmental pollution in coastal areas. The higher relative humidity of Guangzhou (near the second-third class pollution coast-Shenzhen coast with higher phytoplankton biomass) has higher precipitation; in contrast, lower relative humidity of Shanghai (near the inferior fouth class Zhejiang coast) has lower precipitation recent years. Conclusions: Industrial emissions may have two competing effects: one is to promote the growth of phytoplankton and then cause higher seawater evaporation rates and precipitation; another is to decrease water vapour pressure by serious pollution, which then reduces the seawater evaporation rate and precipitation. With temperature increasing, the precipitation is likely to increase only at low pollution area (high latitudes).
\end{abstract}

\section{Keywords}

Industrial Emission, Phytoplankton Biomass, Climate Signature

\section{Introduction}

The dissolution of additional atmospheric carbon dioxide in the ocean will lead to predictable changes in the chemistry of seawater, including an increase in partial pressure of $\mathrm{CO}_{2}$, a decrease in $\mathrm{pH}$, and a decrease in the carbonate ion concentration $\left[\mathrm{CO}_{3}^{2-}\right]$. The possible biological consequences of these changes may increase the 
biomass of marine phytoplankton [1] [2]. The addition of iron to high-nutrient, low-chlorophyll regions induces phytoplankton blooms that take up carbon [3]. The biomass of marine phytoplankton may influence on the sea-surface-temperature gradients as it absorbs more solar energy than pure water. As is well known from El Niño's studies, sea-surface-temperature gradients across the tropical Pacific Ocean can strongly influence global rainfall [4]. Divergent global precipitation changes induced by natural versus anthropogenic forcing have been reported [5]. As a result of global warming, precipitation and typhoon is likely to increase at certain area. However, the mechanisms that human activity is influenced by global climate change are far from completely understood. Industrialization has had an undeniable impact on the global ecosystem; of particular significance to the issue of global warming, the flow of industrial by-products into the ocean can upset the marine ecological balance, which in turn can have a significant effect on climate. We try to analyze the relationship among industrial pollution, phytoplankton biomass and climate signature by Chinese industrialization progresses.

\section{Materials and Methods}

All Chinese industrial pollution data are from Bulletin of Environment in China [6], Bulletin of Marine Environmental Status of China [7]. The meterological data are from China meterological sharing service system [8] and Chinese weather [9].

\section{Results}

Annual average precipitation and temperature in China since the beginning of its period of rapid industrialization [5] are plotted in Figure 1.

Figure 1 shows a significant upward trend in average temperature in China since 1961, but no obvious change to average precipitation. However, if the data are split into two periods (1961-1986 and 1987-2012), a comparison can be made of the average values for the 26 years before and after rapid industrialization. The annual average temperature and precipitation in China before industrialization were $8.52^{\circ} \mathrm{C} \pm 0.24^{\circ} \mathrm{C}$ and $608 \pm 29$ $\mathrm{mm}$ respectively; after industrialization, the annual average temperature and precipitation in China were $9.37^{\circ} \mathrm{C} \pm$ $0.39^{\circ} \mathrm{C}$ and $618 \pm 33 \mathrm{~mm}$ respectively. At the 0.05 level, annual average temperature in China after industrialization is significantly increased by pair-sample t-test, whereas, annual average precipitation in China after industrialization is no significantly difference. However, the distribution of precipitation may be different. It seems that rainfall is more concentrated in certain seasons and certain areas and can lead to floods. Rising concentrations of anthropogenic greenhouse gases in the atmosphere may already be influencing the intensity of rainfall and increasing the risk of substantial damage from the associated flooding [10]. The mechanism may

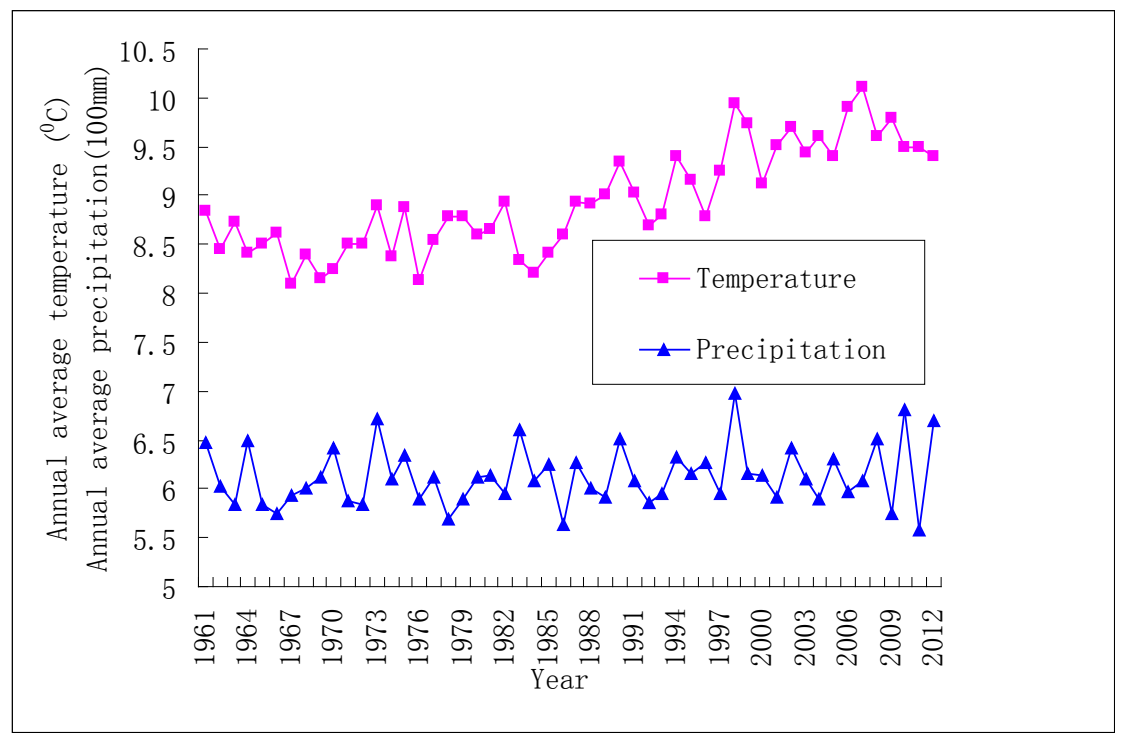

Figure 1. Annual average temperature and precipitation in China before and after rapid industrialization. 
also be related to the phytoplankton growth cycle. When phytoplankton is in its normal growth phase, the relative rate of evaporation of coastal seawater and precipitation will increase. When a phytoplankton outbreak starts to die off, decomposition of the phytoplankton and other dead marine organisms should lead to a reduction in coastal precipitation, and the temperature will rise. So different growth stages of phytoplankton can have opposite effects on the local climate. As coastal environmental pollution will also influence the growth of phytoplankton, climatic characteristics will be different in different polluted coastal areas. In clean coastal areas (such as the Hainan coast with first-class seawater) phytoplankton usually grows with a relatively low density, while in industrial polluted coastal areas (such as the coasts around Shenzhen and Weihai with second- and third-class seawater) phytoplankton grows with a relatively high density in response to the high levels of nutrients in these waters. The relative rate of seawater evaporation and precipitation around polluted areas should be elevated in comparison to clean areas. However, in the most extremely polluted coastal areas (such as typical Zhejiang cost with inferior to fourth class seawater) phytoplankton is actually killed off by oil and other chemicals from industrial contamination. In such areas the relative rate of seawater evaporation, the relative humidity and coastal precipitation should be decreased and the coastal temperature increased with respect to clean areas.

The four photos in Figure 2 were taken at typical Chinese different coastal areas. The first photo, of a coastal area in Hainan province, is representative of a first-class seawater area. The temperature and precipitation of surrounding cities are used as a standard for comparison with more polluted areas. The second and the third photos of coastal areas near Shenzhen city, Guandong province and Weihai city, Shandong province, and are representative of third-class seawater with red tide and green tide respectively. The biomass of phytoplankton in Dayawan Bay, Shenzhen near the photo location was measured as $9.69 \times 10^{6} \mathrm{cells} / \mathrm{m}^{3}$ in 2012, and is showing an upward trend over time [7]. The temperature and precipitation of surrounding cities is expected to be greatly affected. The high biomass of phytoplankton with its high load of chlorophyll will absorb more solar energy, acting somewhat like a greenhouse roof over the affected seawater, driving up humidity in surrounding cities as the evaporation rate of the seawater increases. The result is that the quantity and intensity of precipitation will increase. The temperature will be only subject to minor change as it is regulated by cloud refection and precipitation. The second photo was taken at a coastal area in Hangzhou Bay in Zhejiang province, and shows water quality classified as worse than fourth class with high levels of oil and chemical emulsifier pollution. The biomass of phytoplankton $\left(1.18 \times 10^{6}\right.$ cells $/ \mathrm{m}^{3}$ as measured in 2012) in this area is tending to decrease over time and marine organisms there are generally in an unhealthy condition [7]. The death and decomposition of the majority of marine organisms has caused a film of organic matter that covers the seawater in this area. The high content of chemical pigment granules should absorb more solar energy, while the high content of oil with organic pollutants contributes to a low seawater evaporation rate. The overall result is that the relative humidity of adjacent cities (such as Shanghai) would be expected to decrease [9].

If red and green tides cause most marine organisms to die and decompose to organic matter later, the evaporation rate of affected seawater would be expected to decrease and the temperature to increase during that period. Such changes to seawater evaporation rates can thus influence the relative humidity for nearby coastal cities. As precipitation is related to the change in the humidity at the boundary between regions of hot and cold air, the precipitation in a region of relatively higher humidity area is often greater at a certain temperature. Furthermore, as precipitation can regulate the temperature, the average temperature will tend to increase in those areas near the coast with low seawater evaporation rates and high absorption of solar energy. These predictions are borne out by recent patterns of regional climate; in July 2013, there were more than 10 days with high temperatures $\left(\sim 40^{\circ} \mathrm{C}\right)$ in Shanghai (average temperature is $31.9^{\circ} \mathrm{C}$ and average precipitation is $103 \mathrm{~mm}$ ), while Guangzhou (average temperature is $27.4^{\circ} \mathrm{C}$, and average precipitation is $318 \mathrm{~mm}$ ) and Shenzhen experienced an unusually rainy climate [8].

From the distribution of maximum temperatures recorded in China over the 30 days from July 26 to August 24, 2013 (Figure 3) [9], it can be seen the highest temperature cities (red) in southern China are mainly distributed around Shanghai, near Huangzhou Bay and the Zhejiang coast where seawater evaporation is relatively low. According to the above analysis, industrial pollution and its effects on phytoplankton in coastal seawater may strongly influence the surrounding climate. If the temperature continues to rise in such a large city as Shanghai with high population density in the future, it could well lead to a major natural disaster.

\section{Conclusion}

It can be concluded that Chinese industrialization has led to changes in the marine food chain of coastal areas. 


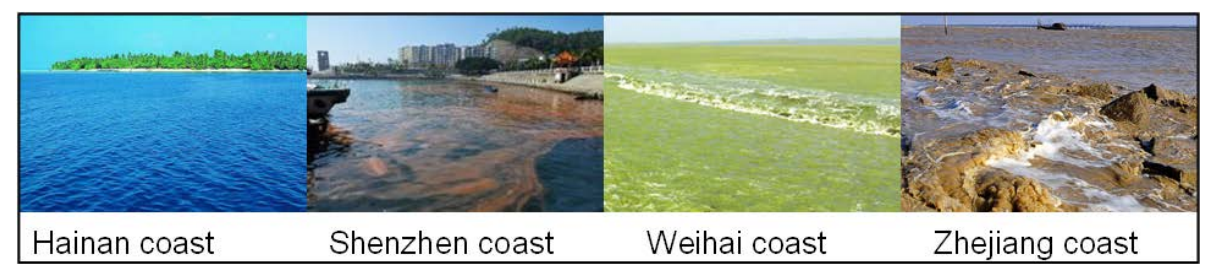

Figure 2. Photos of typical Chinese coastal areas.

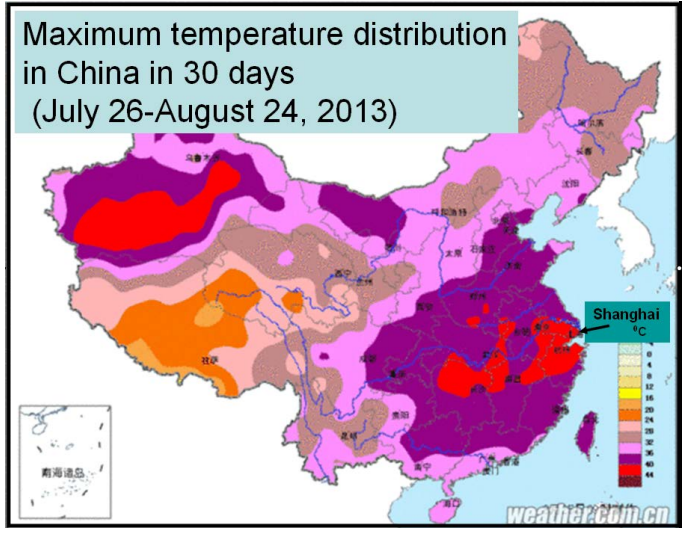

Figure 3. Maximum temperature distribution in China for July 26-August 24, 2013.

The resulting increase in the biomass of phytoplankton causes an increase in the seawater evaporation rate which then contributes to a rise in the humidity in surrounding cities, which in turn can lead to increased intensity and volume of precipitation. However, it is well known that all pollutants in water will decrease the water vapour pressure according to Raoult's law. So industrial emissions may have two competing effects: one is to promote the growth of phytoplankton and then cause higher seawater evaporation rates and precipitation; another is to decrease water vapour pressure by serious pollution, which then reduces the seawater evaporation rate and precipitation. In China, precipitation is becoming more concentrated in some seasons and some areas with higher biomass of phytoplankton. The temperature in seriously polluted costal cities (with below-fourth-class seawater) with less biomass of phytoplankton will increase quickly and the surrounding humidity and precipitation will decrease as industrialization progresses. The total influence on climate of industrialization progresses in China is that annual average temperature after industrialization is significantly increased, whereas, annual average precipitation is no significantly difference. The influence of Chinese industrialization on climate patterns should be taken into account in the study of global climate change. So with temperature increasing, the precipitation is likely to increase only at low pollution area (high latitudes).

\section{Acknowledgements}

This study is supported by National Natura1 Science Foundation of China (Grant No. 11375117).

\section{References}

[1] Shi, D.L., Xu, Y., Hopkinson, B.M. and Morel, F.M.M. (2010) Effect of Ocean Acidification on Iron Availability to Marine Phytoplankton. Science, 327, 676-679. http://dx.doi.org/10.1126/science.1183517

[2] Tortell, P.D. (2008) $\mathrm{CO}_{2}$ Sensitivity of Southern Ocean Phytoplankton. Geophysical Research Letters, 35 , L04605. http://dx.doi.org/10.1029/2007GL032583

[3] Boyd, P.W., Jickells, T., Law, C.S., Blain, S., Boyle, E.A., Buesseler, K.O., et al. (2007) Mesoscale Iron Enrichment Experiments 1993-2005: Synthesis and Future Directions. Science, 315, 612-617. http://dx.doi.org/10.1126/science.1131669

[4] Ropelewski, C.F. and Halpert, M.S. (1996) Quantifying Southern Oscillation-Precipitation Relationships. Journal of Climate, 9, 1043-1059. http://dx.doi.org/10.1175/1520-0442(1996)009<1043:QSOPR>2.0.CO;2

[5] Liu, J., Wang, B., Cane, M.A., Yim, S.Y. and Lee, J.Y. (2013) Divergent Global Precipitation Changes Induced by 
Natural versus Anthropogenic Forcing. Nature, 493, 656-659. http://dx.doi.org/10.1038/nature11784

[6] China Environmental Monitoring Center (2013) Bulletin of Environment in China 2013. http://www.cnemc.cn/publish/totalWebSite/0492/196/newList_1.html

[7] State Oceanic Administration People's of China (2013) Bulletin of Marine Environmental Status of China 2013. http://www.soa.gov.cn/zwgk/hygb/zghyhjzlgb/

[8] China Meteorological Administration (2013) China Meterological Sharing Service System 2013. http://www.cma.gov.cn/2011qxfw/2011qsigx/

[9] China Meteorological Administration (2013) Chinese Weather 2013. http://www.weather.com.cn/

[10] Richard, P.A. (2011) Climate Change: Human Influence on Rainfall. Nature, 470, 344-345. http://dx.doi.org/10.1038/470344a 